\title{
A VIDEO PROJECTION MAPPING CONCEPTUAL DESIGN AND APPLICATION: YEKPARE*
}

\author{
Berna EKİM \\ Maltepe University, Turkey \\ bernaekim@maltepe.edu.tr
}

\begin{abstract}
Can recent developments in video projection techniques aid us in finding new ways of expressing our creativity and creative audio-visual works on a new surface other than the screen? Video Mapping is one of the newest video projection techniques that are used to turn almost any surface into a dynamic video display. The aim of video mapping is to create a physical illusion of images by combining audio-visual elements. Most of the mapping projects are used in fashion shows, corporate events, concerts and theatrical performances. Lately a new trend of video mapping system is being used on architectural and historical structures, buildings and displayed in public spaces to reach a wider audience. This paper will focus on 3 aspects of video mapping and its application; 1) the technical aspects of video mapping and its tools. 2) the conceptual development of the project YEKPARE and the application of video mapping on Haydarpasa Terminal within the Istanbul 2010 European Capital of Culture events. 3) the feedback from the audiences who have experienced the performance and the effects of video mapping.
\end{abstract}

Keywords: creativity, technology, video projection mapping, audio-visual, conceptual design, Yekpare

\section{INTRODUCTION}

\section{Digital Technologies and Art}

Advances in digital technologies are having an undeniable (inevitable) influence on contemporary arts and culture. The world wide web (internet) has not only emerged as an Advanced Mass Communication tool of the $21^{\text {st }}$ Century but also has emerged as a new tool for contemporary artists thus enabling an expansion in the limits of creativity and progression of new forms of authentic expression. Computer technologies can be regarded as a complementary tool for artists in creating new, different and extraordinary artwork. Therefore we can define "digital art" as the art form that deals with and explores the involvement of computers, digital tools, technologies and digitally coded information content as a tool for the conceptual creation, production and exhibition of creative works (Marcos, Branco and Zagalo 2009: 605). For example interactive installations, virtually created environments, digital animations, videos and related software engineering can all be considered under the framework of digital arts. Digital art has become the interface of not only contemporary artwork but also the electronic media era where production is provided by the collaboration of arts, science and technology. "The developments in various tools and interfaces such as computers, photography, video, internet, printers, scanners, processors, calculators and scalers have formed the foundation of digital technologies. In addition, software developed for photographic processing, digital drawing, computer generated imagery and animated production have been widely used in the creation of digital artwork." (Saglamtimur 2010: 220). The screenings of the Artwork created by the use of these tools and software have mostly been projected on a surface (by the help of a projector) accompanied by audio-visual shows, performances and installations. Projection is emerging as an important tool for presentation and communication for all audiences distinctively in the digital era.

\footnotetext{
* Presented on Vizuality Conference: Interactions of Creativity and Images, Vilnius, 2011.
} 
Most of the projections are being used for displaying digital installations and for the audience to view or to observe at the same time. Installation is an art form introduced by the architecture, sculpture and performance artists applied either indoor or outdoor and occupies a certain volume. Installation art shares its origins in the early 1960s, affected by other art movements like Futurism and Dadaism. Especially, Marcel Duchamp was the great example of the artist as curator and master of ceremonies, planning installations of his own work in fine detail, including post humous exhibition in 1969 of Ettant Donnes (Dempsey 2002: 247). Installation has cleared the path for Conceptual Art and Anti-Art movement of the 1960's and introduced the involvement of objects and the audience's participation in the creation process of art. Video installations are the forms of video art in this manner. Emergence of the video art has increased the interest in installations. At the beginning of 1960s, one of the video artists Nam June Paik, was the leader of producing artworks, combining audio and video. Experimental productions by Duchamp and Paik can be considered as the pioneering examples of video and installation art in the digital era today. In this regard we can denote that New Media of the late $20^{\text {th }}$ Century is a composition of video art and its hybrids. Today video art can be produced and screened by the addition of various interfaces and tools as part of a performance or an installation.

In recent years, video installations, also called video projection mappings that are formed relationship between space and visualized materials and displayed on architectural surfaces, buildings. 'space' refers to building's surface, which plays an active role to display and gains recognition as new art forms in public space. This kind of projected performances can also be defined as 'urban screenings'. Urban screens play an interactive role, developing a dynamic digital display to join virtual and urban public space. Yekpare (Monolithic) is one of the urban screening projects, which are displayed on Haydapasa Train Station within the Istanbul 2010 European Capital of Culture events.

\section{VIDEO PROJECTION MAPPING}

Video Mapping is one of the newest video projection techniques that are used to turn almost any surface into a dynamic video display, often at events such as concerts, fashion shows, music festivals, and usually in conjunction with other performing arts. The aim of video mapping is to create a physical illusion of images by combining audio-visual elements. This kind of shows are performed alive, as well as prerecorded, also called as 'real-time' or 'realtime video'. According to C. Paul, use of technology is classified as a "tool" and as a "medium" (Paul 2008: 8). Based on this classification, video mapping projects use technology as a "tool" by composing and editing program to create motion graphics and images, as well as medium by presenting created images to audiences. Projection mapping is the technique of beaming video (with a standard video projector) onto three-dimensional objects such as historical buildings and adjusting and masking the image so that it seems to follow the shape of the target object instead of spilling out onto walls. The result can be surprisingly effective and eye catching as the video is no longer a flat square on the wall but becomes an object in space - an animated sculpture if you will. (http://www.udart.dk/2010/02/17/projectionmapping-on-the-rise/). These $2 \mathrm{~d}$ graphics become $3 \mathrm{~d}$ graphics when it is interacted with applied surface. And then, applied surface gives messages by using audio-visual elements onto its own infrastructure to the audiences.

By exploring the digital technologies, developed concepts are being realized with new tools from multimedia, virtual reality, computer vision, and digital music, sound etc. This coded information is used to create installations and digital artifacts and is being delivered by using various communication infrastructures such as the internet, presentation devices, and storage arrays. Most of the technical aspects for video mapping applications can be divided into subcategories such as motion graphics applications, sound design, real-time video applications, and projections. The main objective of motion graphics applications is the creation of images for audio-visual communication by utilizing various visual effects and digital artifacts. With sound design, the aim is to supplement audio elements for supporting visual show. And real- 
time video applications aid to artist who is in charge on the projection to include simultaneous additions to video installations.

\section{CONCEPTUAL DESIGN AND VIDEO PROJECTION MAPPING: YEKPARE}

Digital art is affected by conceptual art that is an art movement, based on the "concept" or "idea". Thus, the concept is the most important aspect for the composition of the artwork to attract viewers' attention by combining the art and technology. So, we can call all the products as "computer-based art works" which are formed within the framework of digital art. The 'creation process' of designed concept determines the differences of all the products from beginning to end, including the development of new type of technologies, tools and communicates a network between artworks and viewers. Accordingly, video projection mapping is a newest developed method for audio-visual performances to get audiences' attention and to touch their feelings by applying video installations within a concept on public spaces. At the same time, "The architectural dimension of urban space has played an important role in providing a stage for these interactions. Moreover, the architecture itself functions as a medium, telling narratives about the city, its people, and the represented structure of society." (Struppek 2006) Yekpare project is a showcase of Istanbul, the city with its rich history, geographical, aesthetic, and social and political structures.

Conceptual design develops a model of what the artwork will present and how it will be shown in its physical environment that specifies the details of the design such as screen layout, visual effects, main and transit scenes. Building a conceptual stage, the style of a performance is established. The processes of designing a concept are; brain storming, storytelling, sketching, composing the techniques.

(http://www.forum.nokia.com/Design/Design_process/Getting_started/Conceptual_design.xht $\mathrm{ml})$.

\section{Brainstorming / gathering idea}

Brainstorming is one of the important steps for developing the ideas to solve the problem. So, it is important to observe and understand the structure of the problem and gather essential key words to analyze.

\section{Defining scenarios (scripting + storytelling)}

Scenarios are used effectively in conceptual design to explore the ideas for the artwork. It is a construct of a sequence of the story, theme that delivers the message to viewers and builds an emotional connection between the artwork and viewers.

\section{Sketching}

"Sketch; is being explored against a background of past and current practices in analogue and digital media." (Jonson 2002: 246) from this definition, we can say that sketching is an application process to create visual improvisation and to express the way of final artwork that composes in analogue and digital media.

\section{Composing the techniques}

The important issue for an effective performance is to choose the right technique to apply on artwork. In that, the artwork interacts with the audience. This interaction is provided by technique and its components to get feedbacks from the audience.

\section{METHODOLOGY}

In the millennium of communication, technological developments create alternative ways for presenting artwork. Through such developments, Digital art and its branches guide the creation process of the artwork related to its concept. The objective is to communicate and to interact with the audiences and later get their feedback. In this study, the steps of designing a concept for video projection mapping, the newest projection method, is examined with reference to the project; Yekpare (Monolithic). Yekpare was performed within the Istanbul 
2010 European Capital of Culture events. Audience feedback was collected by live interviews during and at the end of the performance and also from questionnaires, which were available in the social media.

\section{A. Analysis Of Yekpare (Monolithic)}

Urban screening / Video mapping / Installation / Performance

Duration: 15:26

Theme: Istanbul

Objective: Installation's objective is to display historical view of Istanbul by using symbolic and narrative images, through the creation of artistic and dramatic space. It aims to reach more viewers and touch their feeling, creating this emotional ambience dramatically.

Performed by Nerdworking (http://nerdworking.org/)

"Yekpare is a story teller to narrate 8500 years' story of Istanbul. The story have symbols from Pagans to Roman Empire, from Byzantine Empire to Latin Empire, and finally from Ottoman Empire to today's Istanbul. A building, which we play on, is Haydarpasa train station has brilliant architectural forms. Connection between Middle East to west as Istanbul since 1906 was formed by Haydarpasa. In 50's; it was a door millions of emigrant. Internal migration triggered chaotic order of Istanbul dialectical daily life scenes. Either its conceptual and political and geographical position or its location's depth of field to watch the entire show from Kadıkoy coast; Yekpare is dramatic as a representation.

First day of the performance is also 47th death day of famous Turkish poet Nazim Hikmet Ran. We started with his quote:" At Haydarpaşa Train Station, in the spring of 1941, it is three o'clock. Sun, exhaustion and rush lay on the stairs" (from his epic novel Human Landscapes. Sun, exhaustion and rush lay on the stairs" (from his epic novel Human Landscapes from My Country)." (by Nerdworking, http://nerdworking.org/)

\section{A1. Brainstorming / gathering idea}

Theme $\rightarrow$ Istanbul $=$ metropolitan city, multi-cultural, history, religion, art, migration .

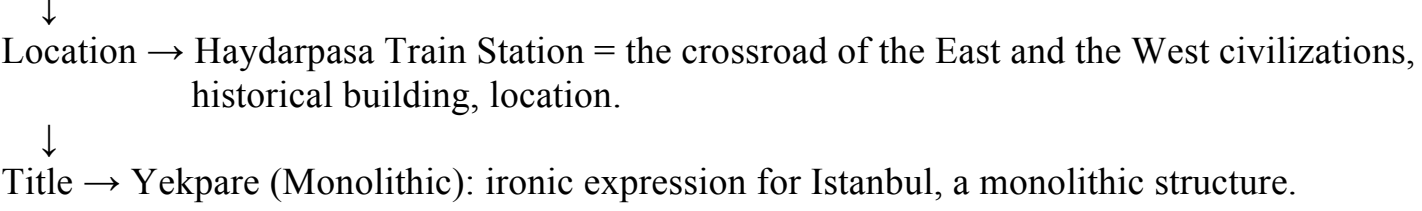

\section{A2. Defining scenarios (scripting + storytelling)}

\section{The Main Scenes}

Scene 1: Sunrise (01:18)

Istanbul is the only place, where joins literally the East meets the West side over the Bosphorus. The story develops over this theme. The Sun is used as a symbol to emphasize the proximity of East and West. Fort this reason, it is located on the scene as an observer. As an appropriate function of the Haydarpasa Train Station, the sun rises from Anatolia and sets at Europe. This scene is supported by light and elegant music to create a mystical overture.

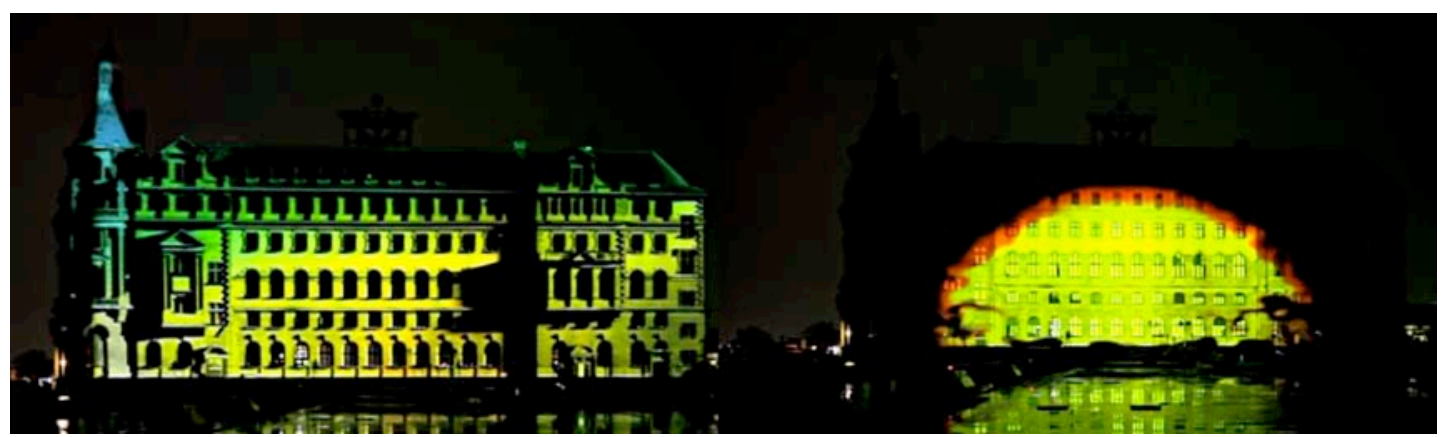


Figure 1. Shots from scene 1 (sunrise)

Scene 2: Transit scene supports with wave visuals and bird sounds.

\section{Scene 3: Byzantine - New Rome - Istanbul (02:47)}

B.C. about 700 years ago, Istanbul was mentioned as Byzantine, having started to use the advantages of being a port city. This location, developing by trade, has been taken the names of the Byzantine - Augusta Antonina - New Rome - Constantinapole - Konstantiniye-Istanbul respectively. This scene begins with shadows of the ships, boats supported by audio elements, which identifies the polyphonicism of the period. The Byzantine walls are created, destroying Haydarpasa Train Station's architectural elements.

The religions existing in Istanbul are visualized with regards to symbolism. By transforming Haydarpasa Train Station's windows into colorful stained glasses, frescos are reflected to the facade.

This process of reflecting advances in a linear time. The images of the period of Istanbul's conquer such as ships going into the Bosphorus; destroyed walls are visualized with sound elements. On the other hand, the aesthetics of Ottoman are shown by "Calligraphic art" to the audiences.

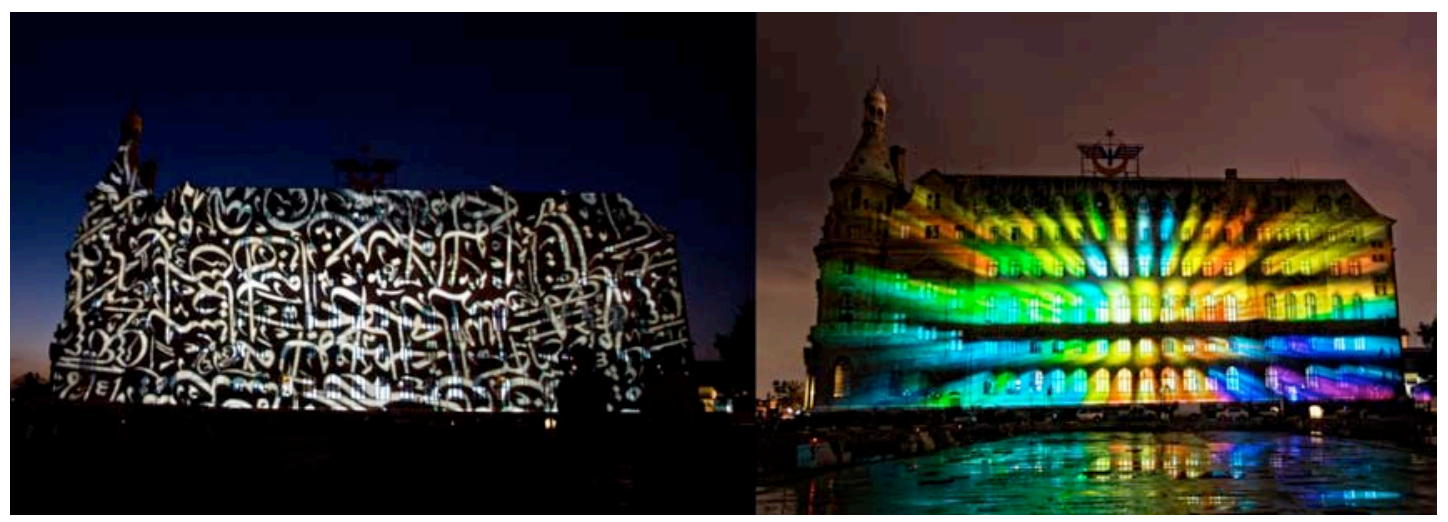

Figure 2. Shots from scene 3 (Byzantine - New Rome - Istanbul)

Scene 4: Watering and Marbling (04:08)

Art is also the element, which has come with history apart from religion and language. The visuals of Marbling on the facade interact with the audiences at the same time with the surface of the sea that composes a strong process.

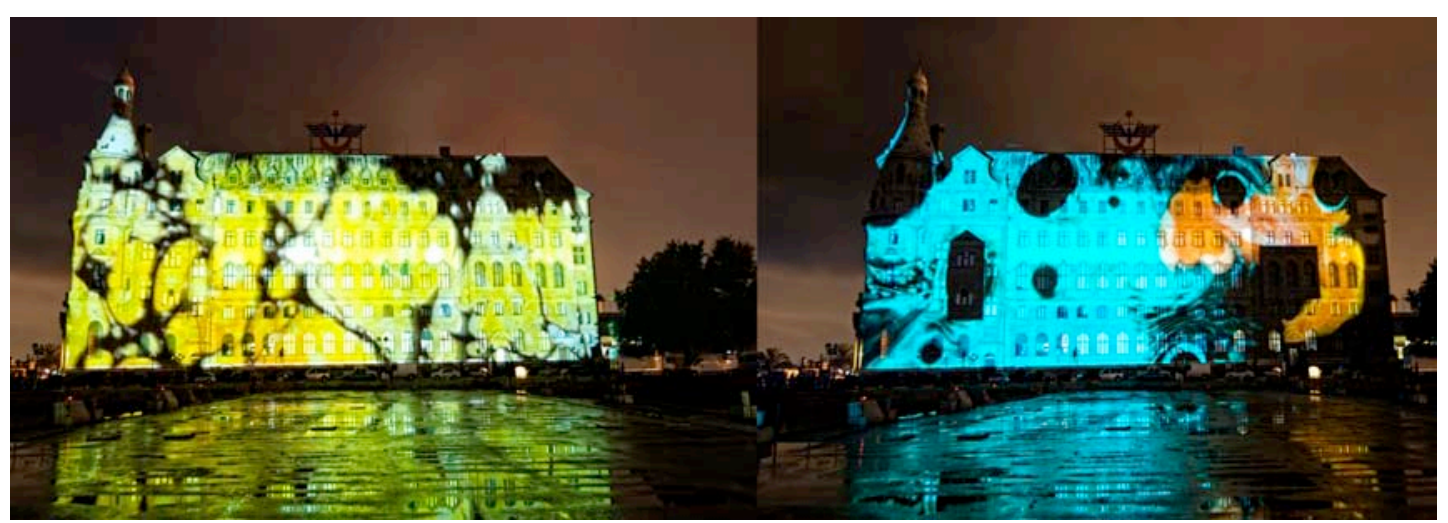

Figure 3. Shots from scene 4 (watering and marbling)

Scene 5: Bridge, Migration and Wagons (08:38) 
There is an animation of the Bosphorus Bridge that connects the European and Asian sides to each other, symbolizes east and west with colors. The east side, with the instrument string instrument and the west side, with the instrument violin is associated.

The importance of the train station is improved with the conjunction of two contents by narrating with the movements of wagons that appears in the middle of the facade. The existing identity of Haydarpasa is visualized with the movements of the wagons. This movements support with the sound of the train and narrate the migration.

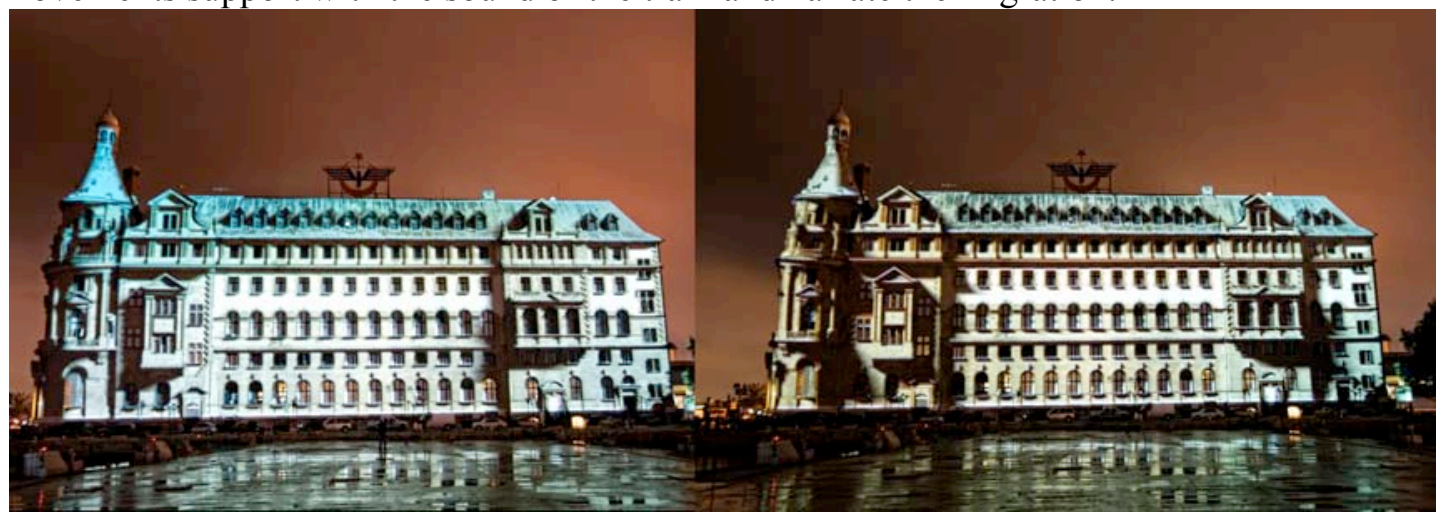

Figure 4. Shots from scene 5 (bridge, migration and wagons)

\section{Scene 6: Windows and Crowded (11:10)}

Increasing migration from the year 1950 the city of Istanbul in different cultures, life values, requirements are changed. Creating people silhouettes to emphasize the station's windows state this description. Istanbul's complex structure is edited with auditory sounds such as traffic sounds and human sounds.

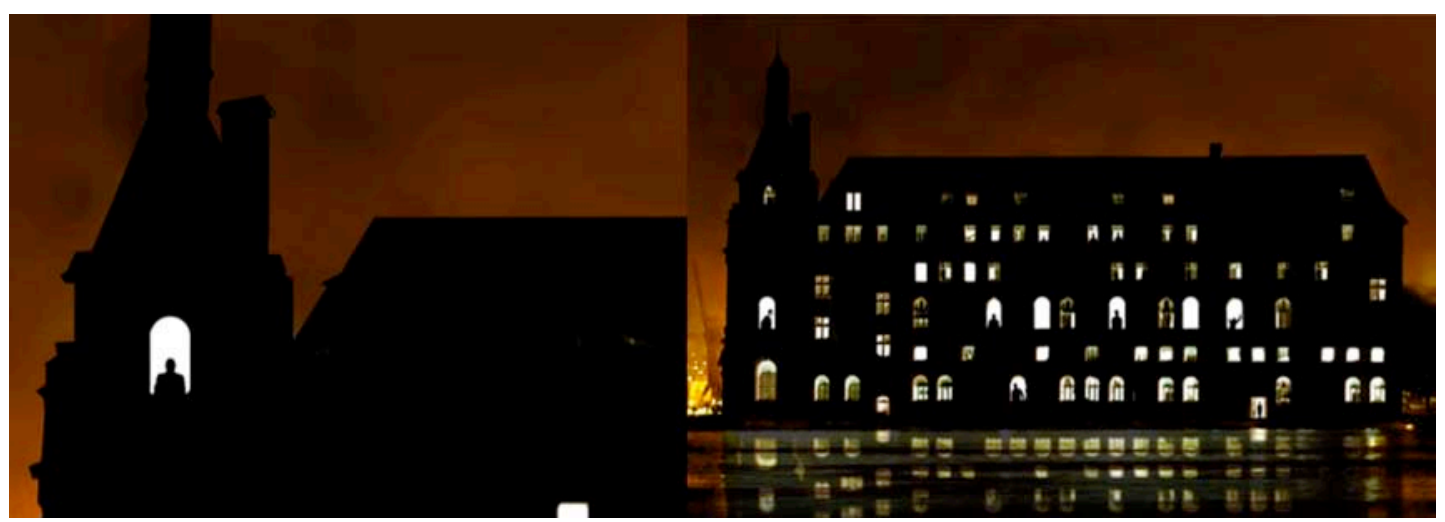

Figure 5. Shots from scene 6 (windows and crowded)

\section{Scene 7: Related Structures; People (12:28)}

Istanbul, is a growing city with its communication around its surroundings every minute and ever day. The established ties between the station windows describe the communication process of the city. At the same time, describes this aesthetic layout and the Internet era of computing with the development of culture in economic systems Networks are changing the structure that created among the people to tell the technology. 


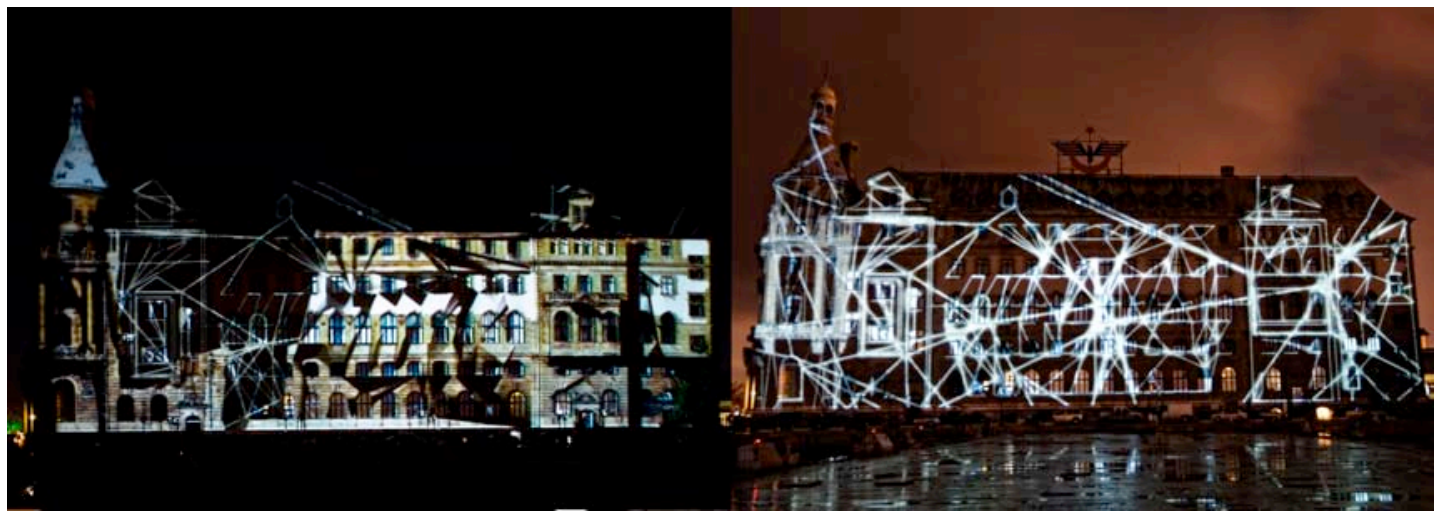

Figure 6. Shots from scene 7 (related structures: people)

\section{Scene 8: Whirling Dervish (14:33)}

Towards the end of the show, Haydarpasa Station tower is resembled a whirling dervishes and rotated in a slow sound effects. Istanbul transforms so far calm place after its complicated and exuberant moments.

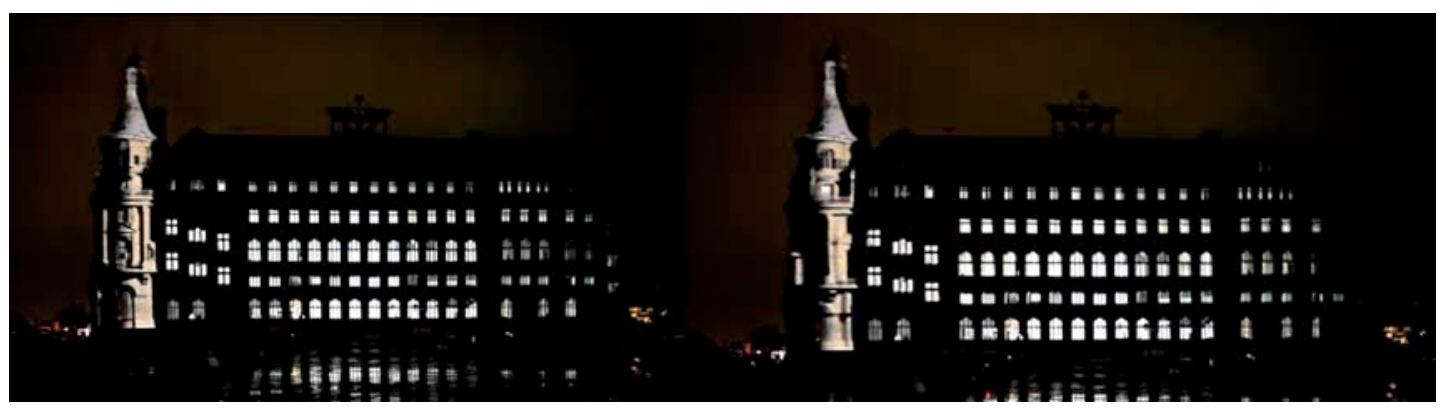

Figure 7. Shots from scene 8 (whirling dervish)

\section{A3. Sketching}

The $3 \mathrm{~d}$ dummy model of the structure, where the video mapping projects will be displayed, is an important element for sketching for audio-visual effects. 3d dummy model of the facade of Haydarpasa is created for testing the visual effects, actions and system of the software. The simulation of the building is a tool for the artists to understand how the visual elements are shown on the surface and the position of the projectors are arranged.

\section{A4. Composing the techniques}

Watchout server system distributes the video equally to the projectors. It provides to transfer the images to the surface.

Projection: 5 (right) +5 (left) SANYO15.000 Ansi Lumen

The distance between the train station and the audiences is $400 \mathrm{~m}$. and $500 \mathrm{~m}$. therefore, the sound links to the image at $330 \mathrm{~m}$. in 1.3 seconds.

24 speakers with 600 and $800 \mathrm{w}$.

Analogue visuals: scene 4.

Software:

3D simulation: 3D Max (animation and modeling software).

Motion graphics: After Effects, Cinema 4D (motion graphics and visual effects software, $3 \mathrm{~d}$ video animator).

Sound design: Abelton (Live is about making music: for composition, songwriting, recording, production, and live performance).

Real-time Video: MxWendler (The image transfers to the surface and then 'key stone' setting is done, where the artist would like to interfere various part of the images such as warming, squeezing etc.) For instance, it is used in scene 6. 
The distribution of the images on Haydarpasa has a mathematical system. An image is divided into 2 parts as left and right. Each part is divided into 4 sub-parts as 1,2,3,4,5,6,7,8,9. Number 10 and 5 are the whole image itself.

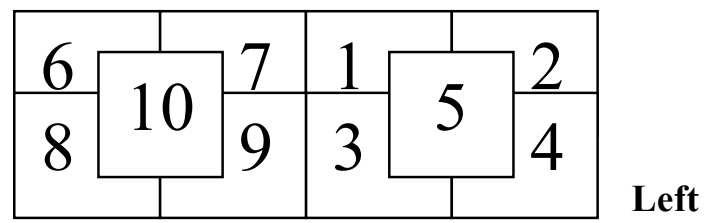

Figure 8. Distribution of the image on Haydarpasa's facade.

Right

\section{SELECTED FEEDBACKS}

(From the interviews, emails and social media)

The Project Monolithic has been watched with a deep interest from its first (June 2010), and the last performance (December 2010). After the performances, more than 100 people have received considerations of the performances through mail, social media and interviews. Some selected feedbacks are below:

Question: Could you share your opinions and feelings with us about Yekpare Project?

1. Viewer: I was really touched. Especially, there were great scenes that reflect Istanbul's motion. I thank to crew, who performed this show.

2. Viewer: That's very beautiful. However, the memory has been fading over the last five months. I think this is the interesting to see light used in that manner. The music, that was really cool. I cannot remember many details but I liked the projection a lot.

3. Viewer: We saw the half of it, the second half. Because, we were too late. And that was curious about, it seems that the light came from inside not from the outside but all those different windows. I thought and asked someone from the inside? Said no. And than I am curious to know how you do that technically. Because I think, you have to rehearse is also but you can do only when people can see it in the evening. I liked it very much. Also the sound, it was really impactable boost.

4. Viewer: We are from Netherlands and I saw the show but I like very much is that they have made such a beautiful use of the architecture of the building. And sometimes vertically, and sometimes horizontally and specifically bar that it seems that were trains on the facade running in opposite direction. I like it very much. It was beautiful with a unity, with a building as it is.

5. Viewer: That's awesome; it is fascinating visualization on an interesting space. I wish I could better interpret some of the abstractions a little better. Like what is happening between 4:10 and 8:30? I can only guess that the colorful chaos is a reflection of how it was, always at war, always a key point of the earth. Would have appreciated detailed shots of the windows at 3:30 for the Christian introduction, which then gets swallowed by Islam very interesting. Close-ups for 11:20 or just a higher rest upload that we can blow up! Great work and had a good time interpreting and watching it.

6. Viewer: The performance has two aspects; in one aspect, the visuals are simply projected onto the building and the building is not a part of the story. It is just a screen where the visuals are projected. This part, I think, a little long. In the second aspect; the building is a part of visuals. That's when the performance comes into life and becomes interesting. Since, the model of the building projected onto the building. It comes into life. I think, this part must be longer. Other than that, I like it. Very smart and interesting.

7. Viewer: This is the first time that I have watched this kind of show. Specially, I really liked the mystical way of the train effects as from 35 th seconds. Audio-visual elements were in a great harmony.

8. Viewer: I was admired by seeing a lot of mapping projects like Yekpare all around the world. I could not watch Yekpare alive but I followed it from internet sources. I have a lot of expectations about Yekpare project. I think the other important times like Istanbul's Conquest, Republic Festival, Canakkale Victory etc. could be also projected. Especially, for 
Istanbul's Conquest, the city walls between Silivrikapi and Belgradkapi could be fit for this kind of projection shows.

9. Viewer: In recent years, I am following up this kind of performances that were screened all around the world. I think Yekpare is one the bests. Especially, Haydarpasa is a nice location for screening.

10. Viewer: The city has been narrated in a perfect way with this installation. I am glad to see the artists, who are interested in his/her city and presented it by showing visual elements.

11. Viewer: Amazing work here. I absolutely love the parts that incorporate the model projection.

12. Viewer; A fascinating and a nice story.

13. Viewer; Awesome show, great editing.

14. Viewer: The place chosen is great. Narrations, sounds, colors, story are also great. Thank you

15. Viewer; What a great, artistic and spectacular way to narrate the story of Istanbul!

16. Viewer; I am really glad to see this kind of show for the first time in Istanbul. It was a nice activity to build morale for Haydarpasa after the fire.

17. Viewer: When I watched the performance, I felt the excitement of living in Istanbul, being native of Istanbul. I could not have a chance to watch the first show that was performed on June. Although the weather is cold, I am really glad to be here tonight. I really liked it.

18. Viewer: I like taking pictures of Haydarpasa. This show was so expressive after the fire. I have taken its photos after the fire and was really great with this performance. I hope Haydarpasa retrieves its original. This is our only desire.

19. Viewer: Mystery, majesty, challenging.

20. Viewer: I really liked the creative idea that approaches to the city in a different way. I had watched the first performance on June and had found it so impressive. I pass by Haydarpasa Train Station almost everyday and had an interaction with it. But we do not always come face to face with this kind of interaction that supported by audio-visual elements in a public space. In a standard monotone life, we cannot make a sense of Haydarpasa. As a result, this performance gets me really excited.

\section{CONCLUSION}

Over the past decade, the growth of digital technologies plays a vital role to create computerbased artworks to display. Digital installations, branches of video arts, are started to apply not only on a flat screen but also on public spaces. These kind installations are called "Video Projection Mapping" and also can be called as "Urban screening". Urban screenings, which are integrated with architecture and technology, give information about the content by bringing together audio-visual elements and presenting them by the help of a projector. These elements emphasize the concept of the artwork that builds relationship between images, perceptions and space. So, it is an outstanding point to apply conceptual design stages brainstorming, defining scenarios, sketching, composing the techniques - in an appropriate and understandable way.

A performed urban screening project within 2010 Istanbul European Capital of Culture events, Yekpare (Monolithic), is produced by video projection mapping technique based on a concept - Istanbul - a datacity to inform society. In this paper, over the theme, Yekpare's scenarios are reflected the form of images, symbols and datas that are related to the context and key words. The images are produced by motion graphics applications, sound design, realtime video applications. Composed images are shown on 3d dummy model of Haydarpasa Train Station's facade to observe the ambience of visual effects, creating dynamic forms in an aesthetic way before live performance.

The essential point of Yekpare project is to explore how such displays can create the emotional links between the space and the audiences. Therefore, audiences' feedbacks were gathered by live interviews during and at the end of the performance and also from questionnaires, which were available in the social media. As a result of feedbacks, most of the 
audiences were affected and excited by the harmony and the unity of audio-visual elements, which narrate the story in a visual show.

\section{REFERENCES}

Dempsey, A. (2002). Styles, Schools \& Movements. London: Thames and Hudson.

Forum Nokia. Conceptual Design. (2011) [interactive]. Internet link: http://www.forum.nokia.com/Design/Design_process/Getting_started/Conceptual_design.xht $\mathrm{ml}$

Jonson, B. (2002). Sketching Now. International Journal of Art \& Design Education 21 (3): 246-253.

Marcos, F., Pedro Segio Branco and Nelson Troca Zagalo. (2009). The Creation Process in Digital Art. Handbook of Multimedia For Digital Entertainment \& Arts. Ed. Borko Fuhrt. NY: Springer Science and Business Media.

Nerdworking. (2011)[interactive]. Internet link: http://nerdworking.org/

Paul, C.2002. Digital Art. London: Thames and Hudson.

Saglamtimur, Z. (2010). Digital Art. Anadolu University Journal of Social Sciences 10 (3): 213-238.

Struppek, M. (2006). Urban Screens - The Urbans Potential of Public Screens for Interaction. Intelligent Agent 6 (2). Special Issue: Papers presented at the ISEA2006 Symposium, August 2006.

Udart, Video Projection and Motion Graph. The Projection mapping on the rise. (2011)[interactive]. Internet link:

http://www.udart.dk/2010/02/17/projection-mapping-on-the-rise/. 